\title{
Vacuum Strength of Two Candidate Glasses for a Space Observatory
}

\author{
T.A. Manning ${ }^{1}$, D.S. Tucker ${ }^{2}$, K.A. Herren ${ }^{2}$ and D.A. Gregory ${ }^{1}$ \\ 1. University of Alabama in Huntsville, Huntsville, Alabama \\ 2. NASA George C. Marshall Space Flight Center, Huntsville, Alabama
}

The strengths of two candidate glass types for use in a space observatory were measured.

Samples of ultra-low expansion glass (ULE) and borosilicate (Pyrex) were tested in air and in vacuum at room temperature $\left(20^{\circ} \mathrm{C}\right)$ and in vacuum after being heated to $200^{\circ} \mathrm{C}$. Both glasses tested in vacuum showed an increase in strength over those tested in air. However, there was no statistical difference between the strength of samples tested in vacuum at room temperature and those tested in vacuum after heating to $200^{\circ} \mathrm{C}$. 
A feasibility study was performed to determine if a large aperture $(\sim 150 \mathrm{~m})$ space surveillance observatory can be manufactured and robotically assembled in space. It was determined that rather than constructing one large optic, a sparse array of one to two meter diameter optics would be more efficient and easier to construct. Due to the massive size of the observatory and the inherent delicacy of large optical elements, the most promising option is to ship raw glass material to a manufacturing device in space, which will produce the optics for later assembly. The vacuum strength testing of glass detailed below was performed to examine some possible effects of processing candidate glass types in space.

It is well established that subcritical crack growth in environments containing water vapor is caused by a stress corrosion reaction between water and the stressed glass [1-5]. It is thus necessary to understand the effect of vacuum on the strength of the candidate glasses. Wiederhorn [6] investigated the effects of a dry environment $\left(\mathrm{N}_{2}\right.$ gas) on crack growth. He demonstrated an exponential dependence of crack velocity on applied load or stress intensity factor. Pukh et al. [7] reported crack growth in vacuum of selected glasses. Wiederhorn et al. [8] looked at crack growth in vacuum for four normal glasses and two glasses exhibiting anomalous elastic behavior. They found that that the normal glasses exhibited subcritical crack growth, however the two anomalous glasses did not. Wiederhorn et al. [9] also found that ultra-low expansion glass (ULE) did not undergo subcritical crack growth in a vacuum.

The samples tested in this study were Corning 7740 (Pyrex) and Corning 7971 (ULE) glasses. ULE was chosen as a candidate due to its near-zero thermal expansion coefficient. Pyrex was chosen because it is relatively easy to process, and its thermal expansion coefficient can be tailored to closely match the observatory support structure. The glass samples were discs $3 \mathrm{~mm}$ thick and $32 \mathrm{~mm}$ in diameter. They were given a 600 grit finish on both sides. Three sets 
of samples of each glass type were tested: one set at room temperature $\left(20^{\circ} \mathrm{C}\right)$ in air, another set at room temperature in vacuum, and a third set at $200^{\circ} \mathrm{C}$ in vacuum. The ASTM F394-78 strength testing technique was used [10]. This method loads the geometric center of a thin disc sample, which is supported axisymmetrically by three ball bearings. The technique provides a uniform load over a relatively large area near the center of the sample and avoids failures from defects on the sample periphery. A test fixture was designed, constructed and installed in a large vacuum chamber. Figure 1 provides a schematic representation of the experimental setup. A linear actuator acting on a large lever supplied the downward force to the vacuum feedthrough load rod (1), which applied the load at the rate of $0.3 \mathrm{~mm} / \mathrm{min}$. A load sensor cell attached to the end of this vertical load rod directly contacted the test sample to guarantee accurate measurements. The sturdy support structure (2) was constructed of stainless steel to prevent fixture movement during load application. Due to the time required to pump down the large vacuum chamber and the duration of time that samples were heated, a tray (3) aligned with the test sample holder (4) was included so that four samples could be tested in series without opening the chamber. Two horizontal feedthroughs (5) on either side of the chamber allowed for broken samples to be dumped and more samples to be pushed onto the test sample holder. The high vacuum level $\left(10^{-6}-10^{-7}\right.$ torr) was maintained by a cryopump. The primary data collected were the force measurements of the load cell as a function of time and were acquired by a LabView program specifically designed for the purpose. Sample temperature was measured via thermocouples, and the vacuum level was determined by standard ion gauges. All samples were stored in a desiccation cabinet until they were brought into ambient laboratory conditions ( $1 \mathrm{~atm}$, $\sim 68 \%$ relative humidity) to be tested, and no sample was exposed to these ambient conditions for longer than ten minutes before it was either broken or placed in vacuum. Samples tested in air 
were removed from the desiccation cabinet one at a time as they were tested. The set of samples tested in vacuum at room temperature were held in high vacuum for 24 hours before testing. For the heated samples, a graphite resistance heater (6) was installed between the tray and test sample holder to heat each sample to $200^{\circ} \mathrm{C}$ for 24 hours in high vacuum. After the samples cooled to approximately $50^{\circ} \mathrm{C}$, they were immediately moved to the sample holder and tested.

The failure stress of each sample was calculated using the equations presented by Kirstein and Wooley [11]. The results are summarized in Table I. The strength of the Pyrex samples tested at room temperature was $62.5 \%$ higher in vacuum than in air. Heating the Pyrex samples to $200^{\circ} \mathrm{C}$ had no discernable effect on their strength compared to the unheated vacuum samples. The strength of the ULE samples tested at room temperature was $95 \%$ higher in vacuum than in air. Heating the ULE samples to $200^{\circ} \mathrm{C}$ resulted in an additional $11.3 \%$ increase over the strength of the unheated vacuum samples. However, this increase is well within the standard deviation. Weibull shape parameters are also included in the Table I summary. A twosided t-test was used for both glass types to determine if there were significant differences of means between the samples tested in vacuum at $20^{\circ} \mathrm{C}$ and those tested at $200^{\circ} \mathrm{C}$ at a 0.01 level of significance. The P-values, which denote the lowest level of significance at which the observed strength values are significant, were calculated to be 0.979 for the Pyrex samples and 0.051 for the ULE samples.

The data here agree well with the results of Wiederhorn et al. [8]. He found that subcritical flaw growth was absent in glasses exhibiting anomalous elastic behavior when crack growth was measured in vacuum. He also found that crack growth was decreased at temperatures near the glass transition temperature. This agrees with Suratwala and Steele's [12] observation that fused silica, which exhibits anomalous elastic behavior, showed a decrease in 
flaw growth as temperature increased. The temperatures in the present study were well below the glass transition regions for Pyrex and ULE, whose annealing temperatures (at which the glass viscosity is about $10^{13}$ Poise) are $560^{\circ} \mathrm{C}$ and $1000^{\circ} \mathrm{C}$ respectively $[13,14]$. This may be the reason there was no observed statistical increase in strength when the glass samples were heated at $200^{\circ} \mathrm{C}$.

There are two more experiments which should be performed. The first experiment would be to heat samples to the glass transition temperature in vacuum and then test their strengths. The second experiment would be to actually melt glass under vacuum, shape and cool it to form glass discs, and then measure the strength of those discs in situ. This latter experiment would be necessary to determine if a near theoretical strength can be obtained for these glasses due to the absence of water and other atmospheric contaminants. If this were indeed the case, then thinner elements could be used to produce the optics for the observatory. 
1. T.C. Baker and F.W. Preston: The Effect of Water on the Strength of Glass. J. Appl. Phys., 17, 179-188 (1946).

2. C. Gurney and S. Pearson: The Effect of the Surrounding Atmosphere on the Delayed Fracture of Glass. Proc. of the Phys. Soc., 62, 469-476 (1949).

3. S.M. Wiederhorn and L.H. Bolz: Stress Corrosion and Static Fatigue of Glass. J. Amer. Ceram. Soc., 53, 543-548 (1970).

4. J.E. Ritter, Jr. and C.L. Sherburne: Dynamic and Static Fatigue of Silicate Glasses. J. Amer. Ceram. Soc., 54, 601-605 (1971).

5. R. Gy: Stress Corrosion of Silicate Glass: A Review. J. Non-Cryst. Solids, 316, 1-11 (2003).

6. S.M. Wiederhorn: Influence of Water Vapor on Crack Propagation in Soda-Lime Glass. J. Amer. Ceram. Soc., 50, 407-414 (1967):

7. V.P. Pukh, S.A. Laterner and V.N. Ingal: Growth Kinetics of Cracks in Glass. Sov. Phys.-Solid State, 12, 881-882 (1970).

8. S.M. Wiederhorn, H. Johnson, A.M. Diness and A.H. Heuer: Fracture of Glass in Vacuum. J. Amer. Ceram. Soc., 57, 336-341 (1974).

9. S.M. Wiederhorn, A.G. Evans, E.R. Fuller and H. Johnson: Application of Fracture Mechanics to Space-Shuttle Windows. J. Amer. Ceram. Soc., 57, 319-323 (1974).

10. ASTM F 394-78 (1996), Standard test method for biaxial flexural strength (modulus of rupture) of ceramic substrates. ASTM International.

11. A.F. Kirstein and R.M. Wooley: Symmetrical Bending of Thin Circular Elastic Plates on Equally Spaced Point Supports. J. Res. Natl. Bur. Stand., 71C, 1-10 (1967). 
12. T.I. Suratwala and R.A. Steele: Anomalous temperature dependence of sub-critical crack growth in silica glass. J. Non-Cryst. Solids, 316, 174-182, 2003.

13. Corning, Inc. 2007. Retreived on January 24, 2007 from

$<\mathrm{http}: / / w w w . c o r n i n g . c o m / L i f e s c i e n c e s / t e c h n i c a l$ information/techDocs/thermalprop.asp $>$.

14. Corning, Inc. 2007. Retreived on January 24, 2007 from

$<$ http:/www.corning.com/specialtymaterials/materials-

products/products_overview/ule.aspx $>$. 


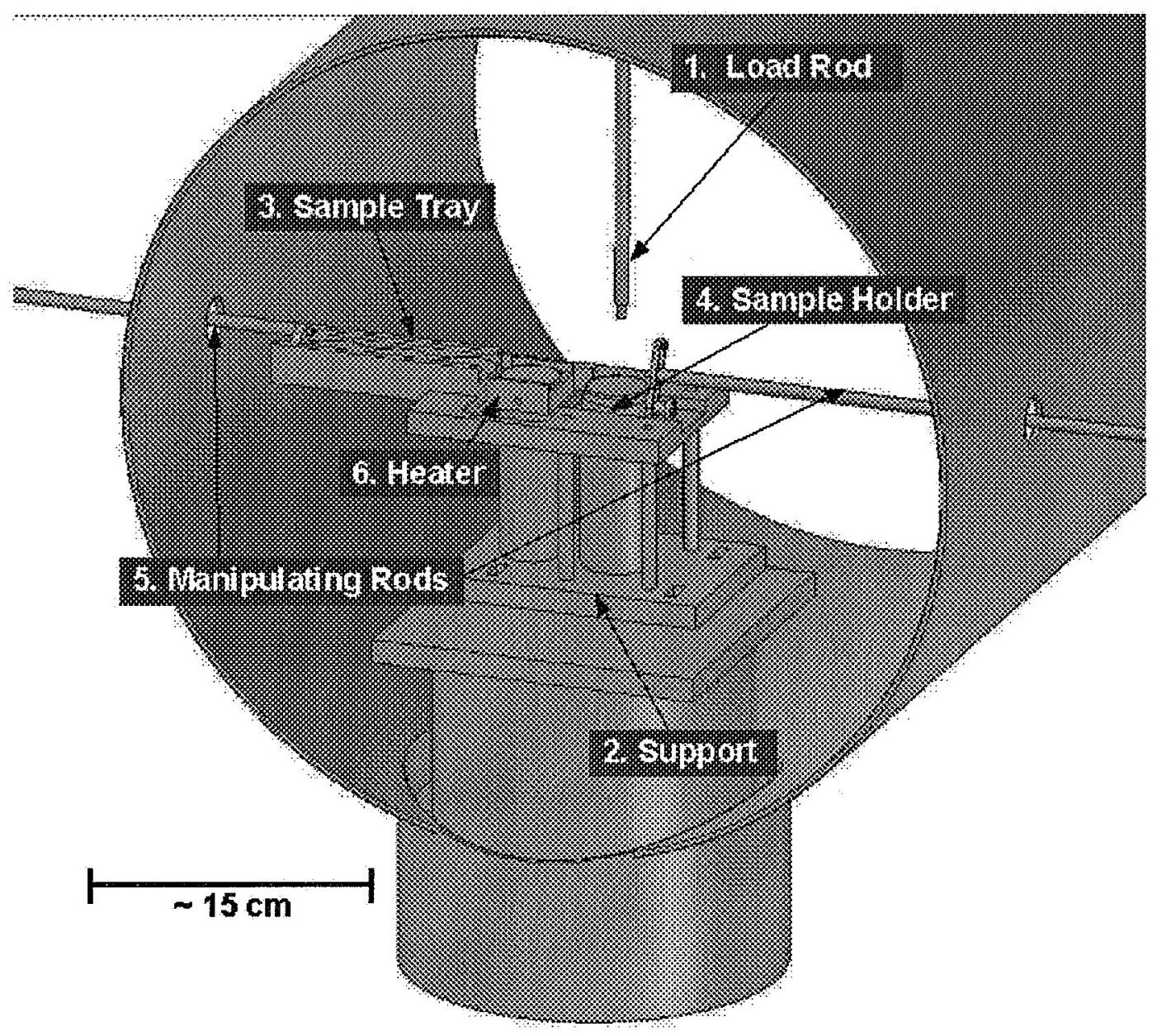

Figure 1. Schematic of Glass Strength Testing Fixture in Vacuum Chamber 


\begin{tabular}{|c|c|c|c|c|c|c|}
\hline $\begin{array}{c}\text { Glass } \\
\text { Type }\end{array}$ & $\begin{array}{c}\text { Pressure } \\
(\mathrm{Pa})\end{array}$ & $\begin{array}{c}\text { Heating } \\
\text { Temperature } \\
\left({ }^{\circ} \mathrm{C}\right)\end{array}$ & $\begin{array}{c}\text { Number } \\
\text { of } \\
\text { Samples }\end{array}$ & $\begin{array}{c}\text { Average } \\
\text { Strength } \\
(\mathrm{MPa})\end{array}$ & $\begin{array}{c}\text { Standard } \\
\text { Deviation } \\
(\mathrm{MPa})\end{array}$ & $\begin{array}{c}\text { Weibull } \\
\text { Shape } \\
\text { Factor }\end{array}$ \\
\hline Pyrex & $10^{5}(1 \mathrm{~atm})$ & 20 & 14 & 80.58 & 9.65 & 9.96 \\
\hline Pyrex & $\sim 10^{-4}$ & 20 & 10 & 130.92 & 22.85 & 7.86 \\
\hline Pyrex & $\sim 10^{-4}$ & 200 & 12 & 130.69 & 17.14 & 8.81 \\
\hline ULE & $10^{5}(1 \mathrm{~atm})$ & 20 & 10 & 68.20 & 12.02 & 5.27 \\
\hline ULE & $\sim 10^{-4}$ & 20 & 10 & 133.52 & 15.26 & 9.64 \\
\hline ULE & $\sim 10^{-4}$ & 200 & 12 & 148.55 & 17.79 & 9.71 \\
\hline
\end{tabular}

Table I. Measured Average Strength Values for Pyrex and ULE Glass Samples 